\title{
SATELLITE REMOTE SENSING AND COASTAL SEDIMENT MONITORING APPROACH WITH NIGERIASAT-2
}

\author{
Henry Olatunbosun ODUNSI, Nigeria \\ Earth Info Services, Lagos
}

Topic: A Innovation in acquisition techniques

\section{INTRODUCTION}

Satellite remote sensing is a recent technology for the monitoring of the earth and its resources. The technique of mapping and monitoring coastal sediments with the satellite requires high-resolution current measurements (Romeiser, 2007). Satellite remote sensing of the coastal environment is important for environmental impact assessment because of its temporal and spatial characteristics. According to Chavez (1997) satellite images of coastal waters provides information about the quality of suspended sediment entering, residing and leaving a given system. The significance of satellite monitoring of coastal sediment is for flood and erosion control management as well as to ensure conservation of natural resources that abound in the coastal zone. Because of the challenges involved in monitoring river discharges in the coastal zone, it is imperative to carry out observations using optical sensors on board satellites for easy identification and analysis of sediment movement pattern along the coastline (Romeiser, 2007). The characteristic nature of the inter-tidal zone is a major factor for consistent monitoring of river discharges in the coastal environment. Caballero, et.al (2012) emphasized that satellite images is useful in areas with high ecological value, for determining the dynamics of sediments in the coastal areas. Sustainable management of the coastal zone is essential because of the dynamic nature in the area. Duffy, et.al (2004) also stated that erosion conditions of sediment transport can be estimated by the spatial gradient of the calculated bed load transport rate. However, in order to have a more detailed information of sediment dynamics along the coastal area, it is important to utilize the hyper spectral imaging technique which is a modern technology for effective acquisition of images. Satellite remote sensing is a cost effective method for coastal dynamics monitoring especially because of the vast area involved. NigeriaSat- 2 is a very highresolution satellite that is highly advanced for its acquisition capacity. This satellite uses the E2v imaging sensors that are integrated into a focal plane array. According to Caballero, et.al. (2012) satellite-borne sensors are an ideal tool for characterizing nutrient loading and sediment dynamics. Therefore, satellite remote sensing and coastal sediment monitoring approach with NigeriaSat-2 is crucial especially for Nigeria in the area of sustainable management of the coastal environment due to the prevailing global climate change and the threat of sea level rise.

\section{METHODS}

The methodology and approach to coastal sediment monitoring with the satellite requires sensors on board satellite in space. These sensors are equipment that gathers and acquires information about the earth from space. Imageries are then generated from the information gathered remotely and are later refined after undergoing image processing and correction stages. Coastal sediment monitoring approach with NigeriaSat-2 entails the acquisition of data with the E2v imaging sensors on board the satellite. The hyper spectral imaging technique of satellite remote sensing gives an assessment of variation in coastal sediment network. This imaging technique acquires images simultaneously in many narrow, contiguous spectral bands and it reveals significant and comprehensive information about the environment. During monitoring and mapping, different wavelengths of light permeate through the water to differing degrees up to 30meters in depth. This help reveal information about the sediment materials, composition and sediment transport pattern.

\section{NigeriaSat-2}

NigeriaSat-2 is a very high-resolution satellite designed for natural resource management and environmental monitoring. NigeriaSat- 2 was launched into space in 2011 and is owned by Nigeria. It is very flexible due to its multi-mode imaging capability. NigeriaSat- 2 is highly advanced for its size, acquiring $2.5 \mathrm{~m}$ pan-chromatic and $5 \mathrm{~m}$ multi-spectral data with special modes such as hyper spectral imagery. The e2v high-resolution focal plane is a CCD (charged-coupled device) imaging sensor. This 
sensor has five multispectral bands with ranges of $450 \mathrm{~nm}$ to $900 \mathrm{~nm}$. It is an $8192 \times 1$ pixel device with $12 \mathrm{pm}$ square pixels.

The sensors on board NigeriaSat-2 are

(1) E-OP1 (Pan achromatic and 4 band colour imager)

(2) E-OP2 (Wide area coverage imager)

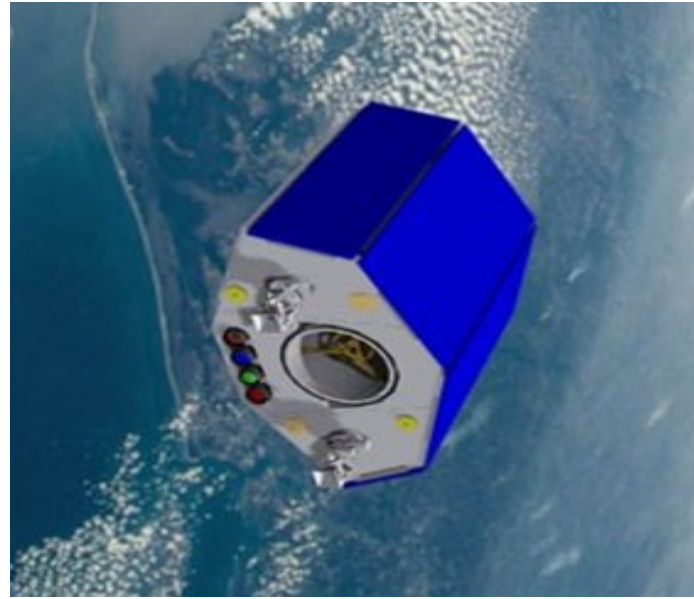

Figure 1: Image of NigeriaSat2

(C)NASRDA Source: www.sstl.co.uk

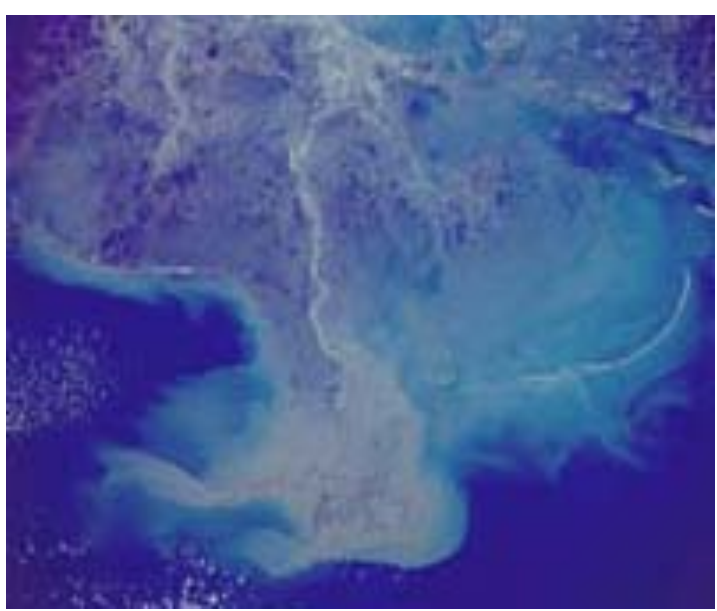

Figure 2: Sediment discharges in the Mississippi Delta (USA)

(c) NASA/ORBIMAGE

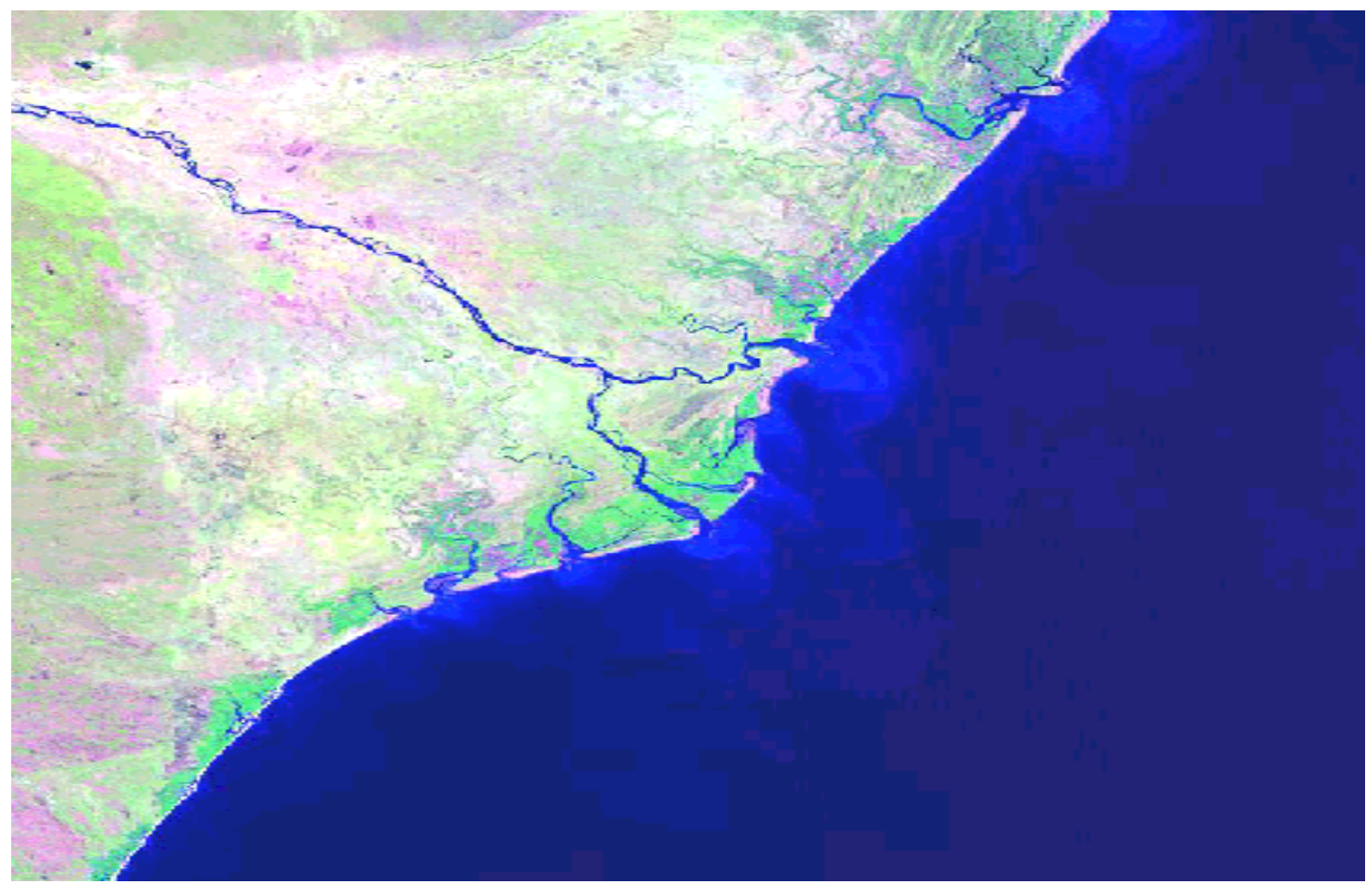

Figure 3: Coastal sediment discharges from Zambezi River Delta, 2000 Source: The World Delta Database 


\section{RESULTS}

Geology of a region is a major factor that determines the sediment materials transported by rivers and streams after weathering process. A typical example is shown in fig.4 where the river discharge enters the estuary. Seafloor sediments in many coastal areas show great spatial and temporal variation but the surface sediments give information about the energy of the coastal waters as well as the movement of materials fig. 3 and fig. 5. Result from research indicates that complicated mixing processes occur at the turbidity front where the river discharge enters the ocean in form of sediment plumes fig.3. Observations have also shown that river discharge during summer is generally at a minimum.

Variation in the sediment network along the coastal waters is basically due to the longshore drift which continually moves sediment material along the coast. This sedimentation problem can be easily identified with the satellite remote sensing method after detailed analysis of the imageries.

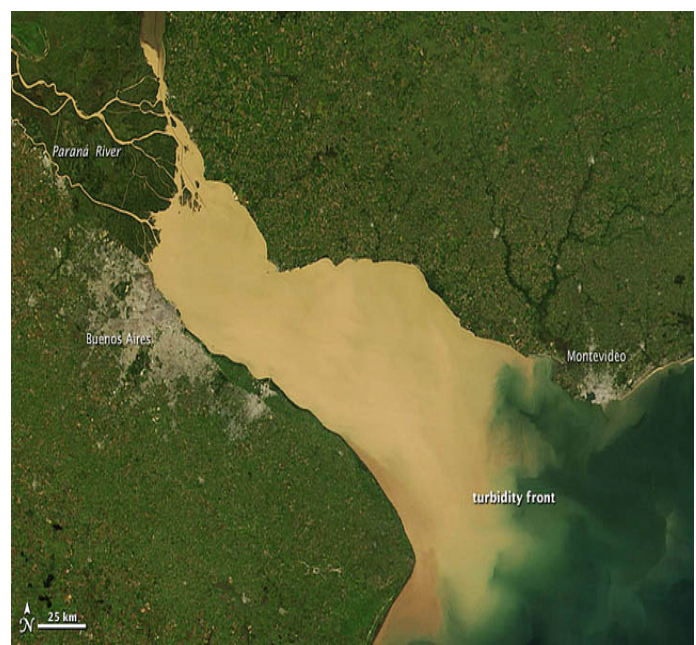

Figure 4: Sediment in the Rio de La Plata, Brazil (c)NASA Earth Observatory Source: Flickr-Photo sharing

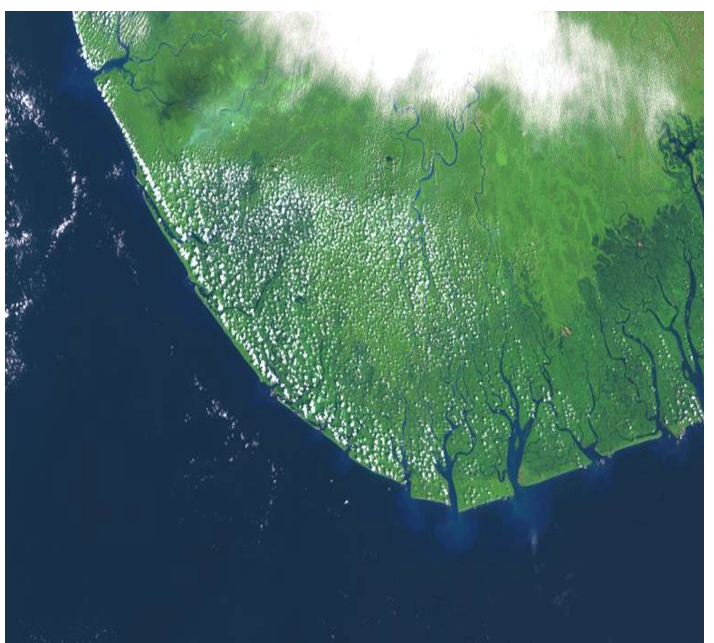

Figure 5: Satellite Image of river discharge in the Niger Delta of Nigeria

(c) Wildworld

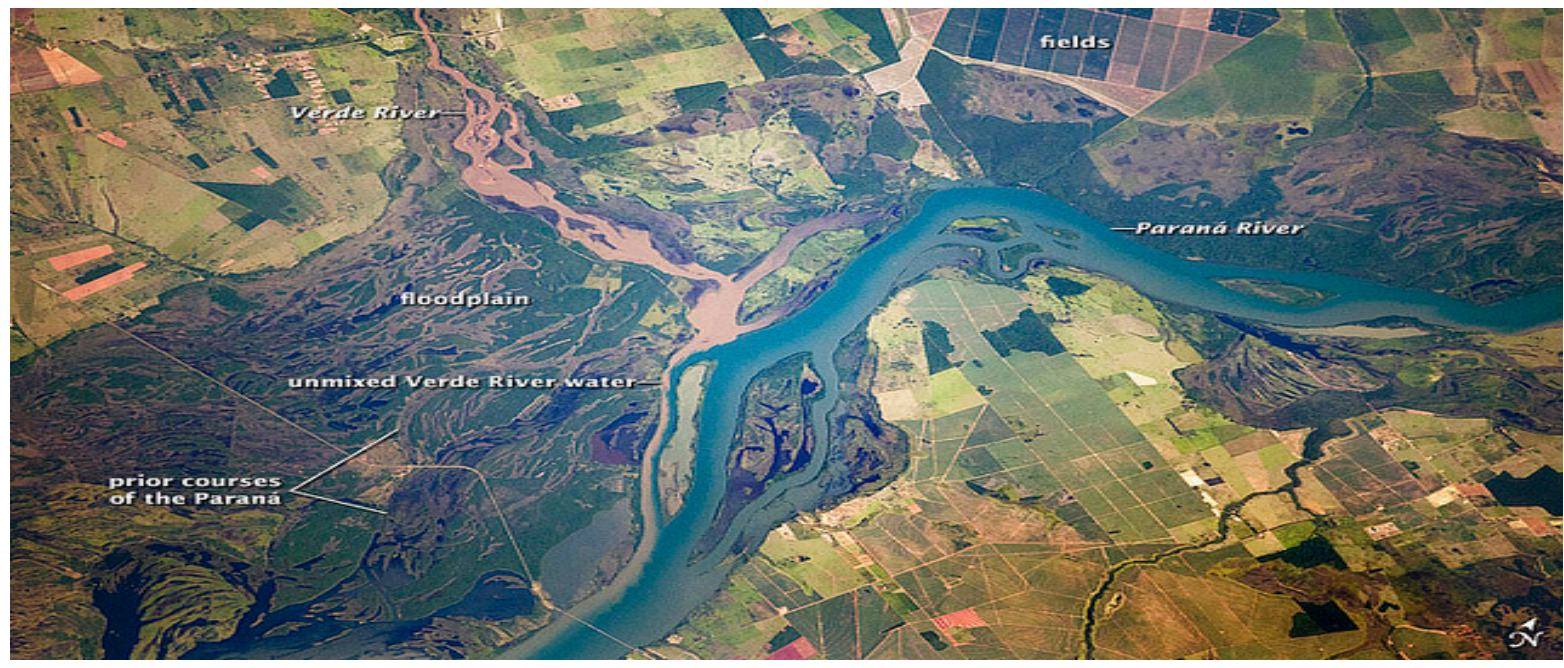

Figure 6: Parana River Floodplain, Brazil (c)NASA Earth Observatory Source: Flickr-Photo sharing 


\section{DISCUSSION}

Coastal sediment monitoring is important because of infrastructural development and anthropogenic activities in the coastal zone. It is essential due to the rapid and constantly changing nature of the coastal zones. Satellite remote sensing is an environmental monitoring system that is valuable during quantification of changes for coastal policy making. It is an important tool for understanding the interactions and processes in the coastal environment. Remote observation with the satellite provides information on spatial variation than the traditional mode of monitoring.

With high-resolution imaging, significant and comprehensive information of the environment is revealed especially when it relates to sediment dynamics. This technology is effective for the identification of potential sedimentation problem and provides useful information for environmental impact assessment during coastal infrastructural developments. However, processing and interpreting the images requires skills and strategies for detection of environmental change. The technique also require gathering of in situ field data for validation of the interpretations from the imageries.

Nevertheless, coastal sediment monitoring approach with NigeriaSat-2 enables preparation and planning for baseline conditions prior to construction works. Establishment of ground controls for environmental monitoring of the changing coastline is critical to marine navigation especially for determination of bathymetry of the waterways. Satellite monitoring and mapping techniques allows different wavelengths of light permeate through the water to differing degrees up to 30 meters in depth. This help in revealing important information of the coastal sediment during dredging and reclamation of the coastal zone.

The threat of sea level rise which is as a result of the prevailing global warming and long-term erosion of sandy beaches is a major factor for considering coastal sediment monitoring. However, withdrawal or removal of sediment deposits from the shoreline and a change in wave transformation pattern is one of the factors that lead to sea level rise. This resultant effect of anthropogenic activities in the coastal zone is the basic reason why satellite monitoring of coastal sediment is important. Sustainable management of the coastal environment require critical measures such as construction of coastal defence structures is which a good way of stopping sediment from being washed away.

\section{CONCLUSION}

Monitoring the process at work in the coastal environment by satellite remote sensing approach is an important step in caring for the sea. Because of the impacts of flooding and coastal erosion on the global economy, agriculture and natural resources that abound in the coastal zone, it is important for governmental agencies and maritime organisations to consider this monitoring approach for the coastal waters in order to avert disaster from the threatening sea level rise.

Due to the importance of the coastal zone in a nation's territorial boundary and the productive level of the coastal zone in total global primary production, it is imperative to consider caring for the sea as a major step in achieving sustainable development. Therefore, the approach of monitoring coastal sediment with a very high-resolution capacity of NigeriaSat-2 cannot be overemphasized. 


\section{REFERENCES}

Bruun, P. "Sea-level rise as a cause of shore erosion", Journal Waterways and Harbours Division, vol. 88(1-3), (1962):117-130.

Caballero Isabel, Edward Morris and Gabriel Navarro, "DEIMOS-1 Satellite Provides Imagery for Coastal management," Sea Technology volume 53, No.2 February 2012.

Chavez, Pat S. Jr. "Mapping Suspended Sediments Using remotely sensed satellite images": San Francisco Bay. Proceedings of the U.S. Geological Survey (USGS) sediment workshop, February 4-7, 1997.

ChevronTexaco CR Report, Case study: Environmental Monitoring with Hyper spectral Imaging, 2002

Demir, H., E.N.Otay, P.A. Work, O.S. Borekci, "Impacts of Dredging on Shoreline Change," Journal of waterways, Port, Coastal and Ocean Engineering. Vol. 130, No.4, July/August (2004):170-178.

Duffy Garret and John Hughes, "Detecting migration of Sand Dunes using spatial correlation," Sea Technology volume 45, No. 10 October 2004.

Evans, M.E, Hall, P.A, Samuels, L. A. et al. "Environmental Application of Hyper spectral Remote Sensing": Managing Liability in an Age of Transparency. Presented at the $17^{\text {th }}$ World Petroleum Congress, Rio de Janeiro, Brazil. (2002)

Felipe, I.P, Dohim J.M, Baker V.R. et al. "Flood detection and monitoring with the autonomous Sciencecraft experiment on board EO-1," Remote Sens. Environ. 101, (2006):463-481.

Larson Robert, Morang Andrew and Laurel Gorman, "Monitoring the Coastal Environment Part II": Sediment Sampling and Geotechnical Methods. Journal of Coastal Research, 13(2), (1997):308-330.

Manikiam, B., Honne Gowda, Manavalan, P. et.al "Study of Sediment dynamics using Satellite remote Sensing": Indian Space Research Organisation, Bangalore, India. 2002

National Space Research and Development Agency (NASRDA): "NigeriaSat1 - A Medium Resolution Satellite for Earth Observation," 2003.

Romeiser Roland, "High-Resolution Imaging of current fields from satellites," Sea Technology volume 48, No.9 September 2007.

Rong-Rong Li, et al. "Remote Sensing of Suspended Sediments and Shallow Coastal Waters," 2003

Sediment monitoring, 2009, http://www.grasdk.com

Smith Randal, "Introduction to Hyperspectral Imaging," 2012, http://www.microimages.com

Space blog, "Blogging the changing economics of Space," NigeriaSat-2 captures stunning high resolution images March 19, 2012

www.digitalglobe.com

www.mongabay.com (2004-2011)

Xiao, L. "NigeriaSat-2 Satellite Uses the E2v Imaging Sensors," Industry News 2011-8-30 


\section{BIOGRAPHIES}

Henry Olatunbosun ODUNSI is the Director/CEO at Earth Info Services. He has more than 10years experience in dredging and reclamation survey, including 5years work experience with Dredging International. He holds a B.Sc degree in Botany from the University of Lagos - Nigeria, a second B.Sc degree in Surveying from the University of Lagos and an M.Sc degree in Surveying and Geoinformatics from the same University of Lagos. He was a PhD researcher at Cardiff University's School of Earth Sciences for a year. His research Interest includes airborne LIDAR bathymetry for coastal zone monitoring and management, satellite remote sensing, Geophysical acquisition survey, dredging and environmental management.

CONTACT DETAILS

Henry Olatunbosun ODUNSI

Earth Info Services

10, Ogundele Street, ewutuntun, Oshodi, Lagos

NIGERIA

Tel.:+234(0)8023202201

Fax: NA

Email: earth_info2002@yahoo.ca

Web site: http://www.earthinfoserv.com.ng

LinkedIn account: earth_info2002@yahoo.ca

Facebook account: henriodunsi@live.com

Twitter account: odunsiHO@live.com 